\title{
Regional moisture budget associated with drought/flood events over China
}

\author{
Shuang Qiu', Wen Zhou' ${ }^{1 *}$ Marco Yu-Ting Leung ${ }^{1}$ and Xiuzhen Li
}

\begin{abstract}
In this study, long-term (1961-2011) variations in the moisture budget and drought/flood events in six subregions of China are analyzed. Water vapor is mainly transported zonally during winter, while meridional transport is much stronger during summer. During winter, both the input moisture from the western boundary and the output moisture from the eastern boundary are slightly weakened; thus, the total amount of regional moisture in these subregions does not change much in eastern China. During summer, the decline in input moisture from the south is slightly weaker than the decrease in output moisture via the northern boundary; therefore, the net moisture budget is slightly increased in eastern China, resulting in more flood events during recent decades in this region. Generally, China tends to suffer much less drought risk and higher flood risk in the mature winter and decaying summer of El Niño; the opposite impact appears during a La Niña event, but with lower intensity.
\end{abstract}

Keywords: Water vapor budget, Drought and flood events, Enso, Standardized Precipitation Index

\section{Introduction}

As China has a very large territory, it has great climate diversity. Generally, it can be divided into three climate zones, including the monsoon zone, the arid zone, and the highland zone. Each zone can be further divided into several regions, such as the tropical, subtropical, and midlatitude monsoon regions within the monsoon zone. Different regions have different climate features, such as the enhancement of summer precipitation over southeast China and the decrease in summer precipitation over southwest China during the past decades. It is important to study why the climate differs in different regions, and how it will change in the future.

It is generally believed that excessive rainfall often results in floods, while the long-term lack of rain can lead to droughts. Large-scale droughts and floods may bring severe damage to agricultural and industrial activities. Floods can last for several months, such as the severe floods of the Yangtze River in 1991, 1996, and 1998 (Zhai et al. 2005). Compared to floods, droughts can last for a longer time, even more than 1 year, such as the extreme drought over southeastern China that persisted

\footnotetext{
* Correspondence: wenzhou@cityu.edu.hk

${ }^{1}$ Guy Carpenter Asia-Pacific Climate Impact Center, School of Energy and Environment, City University of Hong Kong, Tat Chee Ave., Kowloon, Hong Kong SAR, China

Full list of author information is available at the end of the article
}

for 24 months during 2003 to 2005 , making it the worst drought since 1960 (Lin et al. 2012). Precipitation is the dominant parameter affecting drought and flood events. Investigations have found that northern China has become increasingly drier, while in central China, rainfall has been on the rise (Lei and Duan 2011). In eastern China, there has been more rainfall over the Yangtze River valley and less over the Yellow River and Huai River valleys in recent decades, which indicates that the rainy belt is shifting from north to south over eastern China. Moreover, the decadal variation of precipitation also shows a positive-negative-positive pattern over eastern China, which means that when there is a wetter period in the Yangtze River valley, there is a drier period in both northern and southeastern China (Zhao and Zhou 2006; Ding 2007).

Water vapor transport is very important to regional precipitation, as it provides a much greater moisture supply than local evaporation (Trenberth 1999). Previous studies have indicated that variation in precipitation over East Asia is highly affected by variation in water vapor flux (e.g., Li et al. 2011; Wang and Chen 2012; Wei et al. 2012). During summer, water vapor transport is highly associated with large-scale monsoon circulations; thus, water vapor transported to China comes mainly from three major regions: the western Pacific Ocean, the 
South China Sea, and the northern Indian Ocean (Simmonds et al. 1999; Ding and Sun 2001). During winter, water vapor is mainly transported zonally, from west to east with northwesterly air flow (Zhang et al. 1997; Jhun and Lee 2004). While previous studies have focused mainly on the convergence and divergence of water vapor in one region, the regional water vapor balance and moisture budget via each boundary as well as their variations in the past decades are in need of study. In this study, a simple and clearly regional deviation is used to separate China into six subregions, each with different climate characters, and the water vapor budget is calculated in each subregion to study its contribution to the precipitation variation. Studying the variation of water vapor transport can help us understand precipitation variability as well as the features of flood and drought events during the past decades.

The El Niño-Southern Oscillation (ENSO) is a very important climate driver that can influence variations in precipitation by modulating the related atmospheric circulation on an interannual timescale; therefore, it is important to study drought and flood risks during different ENSO stages in different subregions. El Niño winters usually induce more precipitation over East Asia, which is contributed by the weaker East Asian winter monsoon (Wen et al. 2000; Wang et al. 2008). And the influence of El Niño can persist into the following summer, with much more rainfall in the Yangtze River region (Zhang et al. 2007). The situation reverses during La Niña events. In this study,
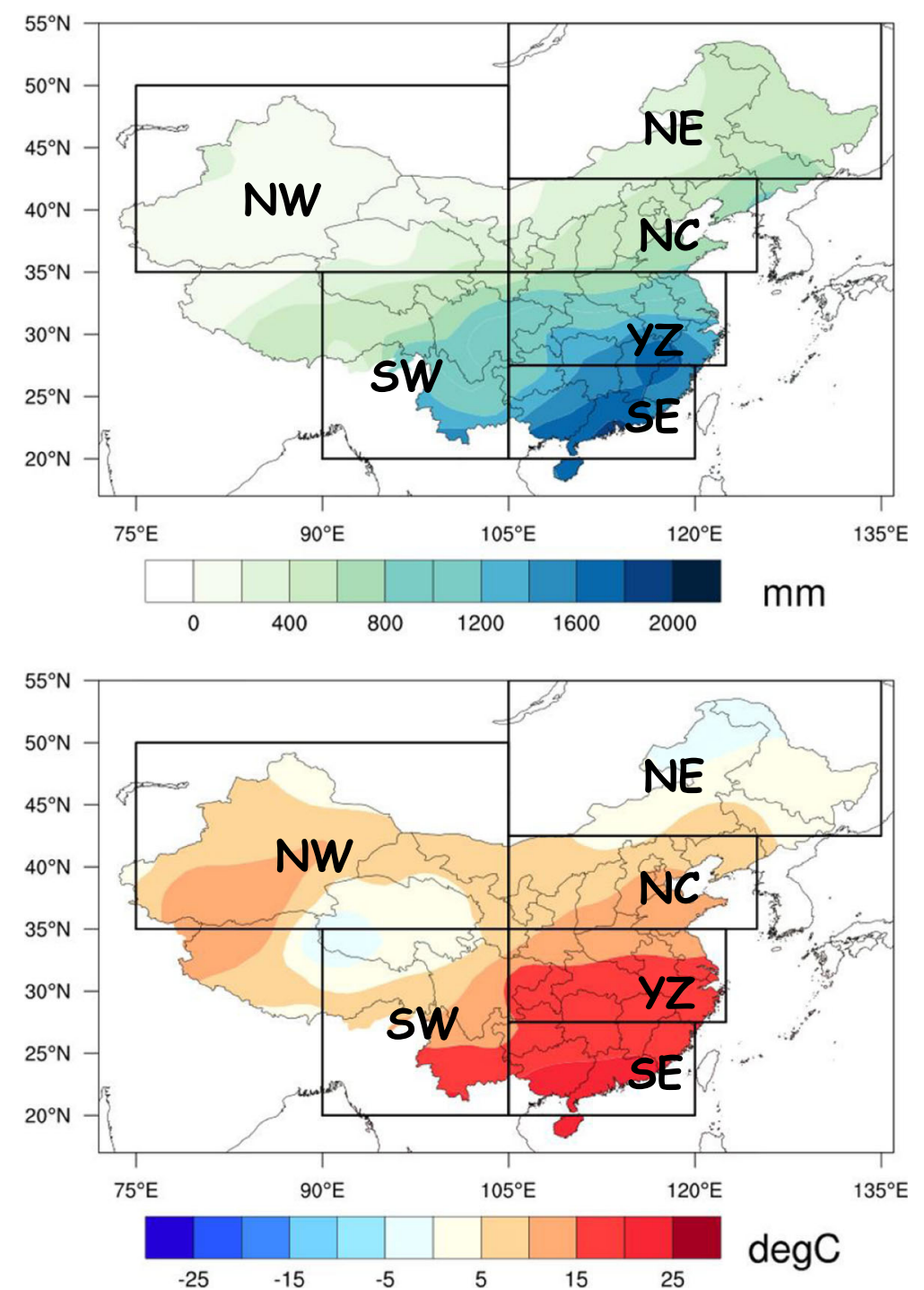

Fig. 1 Six subregions of China: NW (northwest China $35^{\circ}-50^{\circ} \mathrm{N}, 74^{\circ}-105^{\circ} \mathrm{E}$ ), SW (southwest China $20^{\circ}-35^{\circ} \mathrm{N}, 90^{\circ}-105^{\circ} \mathrm{E}$ ), NE (northeast China $42^{\circ}-55^{\circ} \mathrm{N}$, $105^{\circ}-134^{\circ} \mathrm{E}$ ), NC (north China $35^{\circ}-42^{\circ} \mathrm{N}, 105^{\circ}-125^{\circ} \mathrm{E}$ ), YZ (Yangtze River valley $28^{\circ}-35^{\circ} \mathrm{N}, 105^{\circ}-123^{\circ} \mathrm{E}$ ), and SE (southeast China $20^{\circ}-28^{\circ} \mathrm{N}, 105^{\circ}-120^{\circ} \mathrm{E}$ ) 
we calculated the flood and drought risks during ENSO conditions in different subregions in China in order to elucidate the strength of the influence of ENSO on precipitation in different parts of China.

This study is focused on long-term changes in drought and flood events in different subregions as well as the associated regional moisture budget. The remainder of this paper is organized as follows: First, the datasets and methodologies are introduced. Then long -term changes in rainfall and temperature over different subregions are examined, drought and flood events of the past decades are also studied, and spatial variation in water vapor transport in the various subregions is further described. A discussion and summary follow in last section.

\section{Methods/Experimental \\ Data}

In this study, daily precipitation data are obtained from the Climate Data Center, China Meteorological Administration (CMA). Fifty-two years (1961-2011) of continuous observation data from 526 (out of 756) stations are selected in this study. Observation data that contain more than 20\% missing days from more than 1 month in a year or that have more than $10 \%$ missing days in a year are removed from the dataset. Temperature data are the daily mean

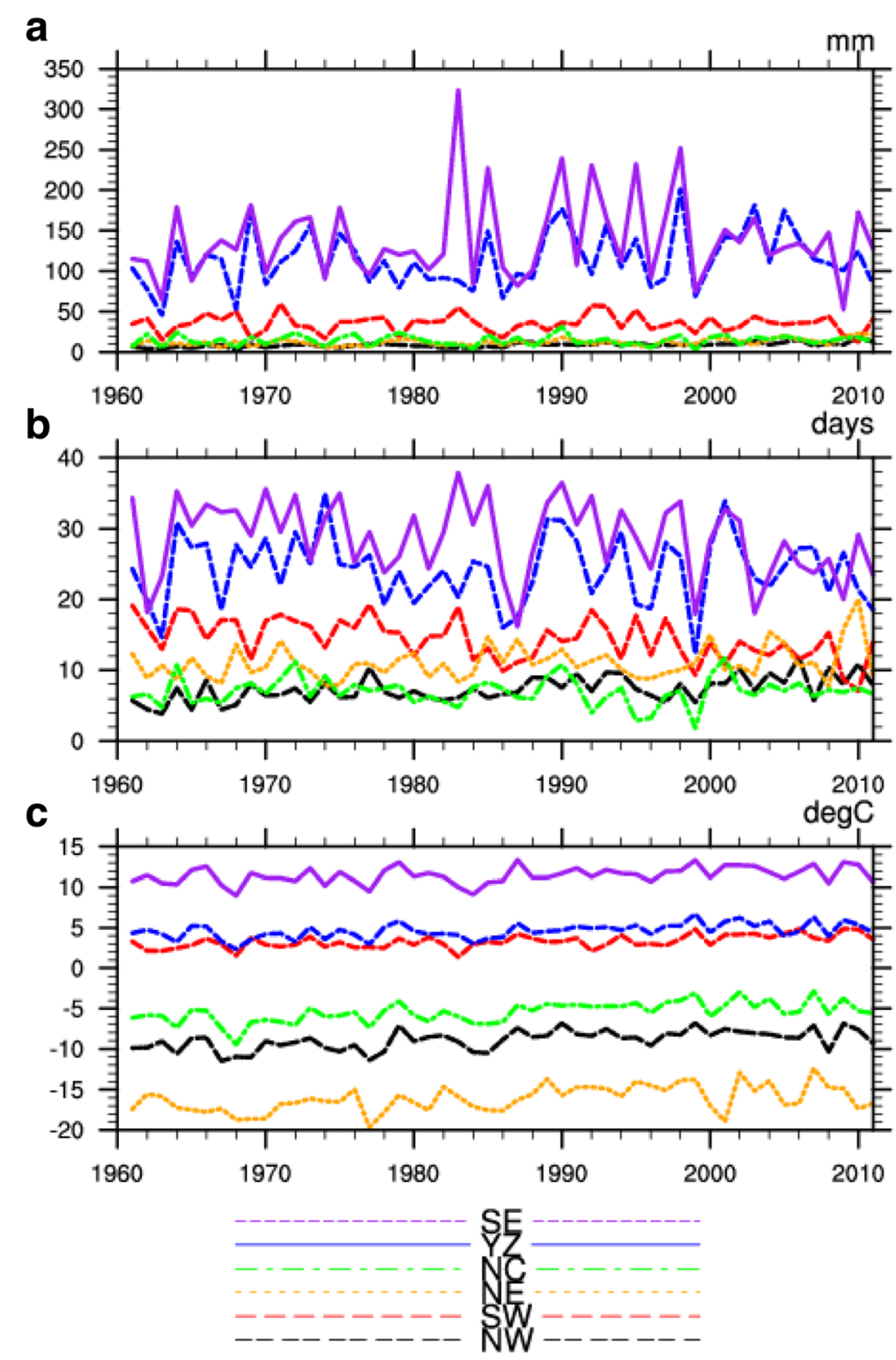

Fig. 2 Subregional climate changes from 1961 to 2011 in winter a rainfall amount, b rainfall days, and c temperature 
surface air temperature (SAT) series from 545 out of 756 National Standard Stations in China during 1961-2011 from CMA. Missing records are defined as more than 10 missing days in 1 month or more than 30 missing days in 1 year.

The dataset used to calculate the water vapor flux is the gridded data from the National Centers for Environmental Prediction-National Center for Atmospheric Research (NCEP-NCAR) for the years from 1960 to 2011 (Kalnay et al. 1996). The horizontal resolution of this dataset is $2.5^{\circ} \times 2.5^{\circ}$ latitude-longitude, and the physical parameters used in this study contain zonal wind, meridional wind, and specific humidity.

\section{Regional definitions}

As China has a very large territory, the climate in different regions is modulated by different systems. Therefore, to better understand the regional features of precipitation in China, it is helpful to divide it into subregions. Using both the climatological mean precipitation and the temperature increase from northwest China to southeast China (Fig. 1), as in the 2013 China Climate Bulletin (CMA 2014) and also in Ma et al. (2015), we divided China into six subregions. In this way, different subregions show different climate characteristics-for example, northwest China is cold and dry, and southeast China is relatively warm and wet. We also made small modifications for latitude and longitude when dividing into subregions for the convenience of calculating the moisture budget, these are: NW (northwest China $35^{\circ}-50^{\circ} \mathrm{N}, 75^{\circ}-105^{\circ} \mathrm{E}$ ), SW (southwest China $20^{\circ}-35^{\circ} \mathrm{N}, 90^{\circ}-105^{\circ} \mathrm{E}$ ), NE (northeast China $42.5^{\circ}-55^{\circ} \mathrm{N}, 105^{\circ}-135^{\circ} \mathrm{E}$ ), NC (north China $35^{\circ}-42.5^{\circ} \mathrm{N}, 105^{\circ}-125^{\circ} \mathrm{E}$ ), $\mathrm{YZ}$ (Yangtze River valley $27.5^{\circ}-35^{\circ} \mathrm{N}, 105^{\circ}-122.5^{\circ} \mathrm{E}$ ), and SE (southeast China $\left.20^{\circ}-27.5^{\circ} \mathrm{N}, 105^{\circ}-120^{\circ} \mathrm{E}\right)$.

\section{Water vapor flux}

The water vapor flux $(\vec{Q})$ in the troposphere is calculated by using the vertical integral from the surface to $200 \mathrm{hPa}$ :

$$
\vec{Q}=-\frac{1}{g} \int_{P_{\text {surf }}}^{P_{\mathrm{top}}} \vec{V} q d p
$$

where $g$, $q$, and $\vec{V}$ are gravity, specific humidity, and the horizontal wind vector, respectively, $P_{\text {surf }}$ is the surface pressure, and $P_{\text {top }}$ is the pressure at $200 \mathrm{hPa}$ (Trenberth 1991).

The water vapor transported across each boundary is calculated following the method of Schmitz and Mullen (1996):

$$
N=\frac{1}{g} \int_{L} \vec{Q} \times \vec{n} d l
$$

where $L$ and $\vec{n}$ are the length and pointing normal vector of each boundary, respectively.

\section{Flood and drought risks under ENSO conditions}

The risk of drought and flood is defined by a widely used approach, using the ratio of the probability of SPI $\geq 1.0$ (SPI) under ENSO to that under all conditions for flood (drought) risk (Bowman and Azzalini 1997; Li et al. 2015). An ENSO condition is defined when the winter Niño 3.4 index is greater/smaller than its 0.7 standard deviation. A value of flood (drought) risk greater than 1.0 indicates a higher than normal flood (drought) risk; a value less than -1.0 indicates a higher than normal drought (flood) risk. Higher flood risk is displayed in blue, and higher drought risk is in red in Fig. 10

Table 1 Trend coefficient of precipitation amount ( $\mathrm{Pa})$, precipitation days $(\mathrm{Pd})$, and temperature $(\mathrm{T})$ during winter and summer in six subregions

\begin{tabular}{|c|c|c|c|c|c|c|}
\hline \multicolumn{3}{c}{ Winter } & \multicolumn{3}{c}{ Summer } \\
\hline \multicolumn{1}{c}{ Pa } & Pd & T & Pa & Pd & T \\
SW & 0.128 & 0.066 & 0.045 & 0.262 & 0.016 & 0.025 \\
NE & -0.019 & -0.105 & 0.032 & -0.945 & -0.112 & 0.019 \\
NC & 0.135 & 0.043 & 0.052 & -0.605 & -0.131 & 0.030 \\
& 0.022 & -0.004 & 0.050 & -1.213 & -0.123 & 0.019 \\
YZ & 0.566 & -0.012 & 0.029 & 2.007 & 0.021 & 0.003 \\
SE & 0.329 & 0.105 & 0.026 & 1.160 & -0.054 & 0.013 \\
\hline
\end{tabular}




\section{Results and Discussion}

Long-term changes in precipitation and temperature in different subregions

In order to better understand changes in the characteristics of precipitation over China, the geographic distribution of the long-term (1961-2011) mean precipitation amount and the number of precipitation days, as well as the temperature variations in different subregions, is briefly discussed. A precipitation day is defined when the precipitation is $\geq 0.1 \mathrm{~mm} /$ day.

Winter precipitation is relatively greater in SE and YZ, where it can exceed 300 and $200 \mathrm{~mm}$, respectively, in a particular year, and during 1980-2000, the precipitation was greater than in any other period.
Precipitation is very low in north and west China; it reaches only $50 \mathrm{~mm}$ over most of SW and is below $20 \mathrm{~mm}$ in NC, NE, and NW each year (Fig. 2a). Variation in the number of precipitation days (Fig. 2b) is highly related to the annual precipitation amount, with 20-40 days in SE and YZ, only 10-20 days in $\mathrm{NE}$ and SW, and fewer than 10 days in NC and NW each year. The distribution of temperature decreases from south to north and from east to west. The highest mean temperature is about $10^{\circ}$ in $\mathrm{SE}$, and the lowest mean temperature is about $-17^{\circ}$ in $\mathrm{NE}$; temperature in all six subregions has shown an increasing trend during the past decades (Fig. 2c). The trend coefficients in different subregions are listed in

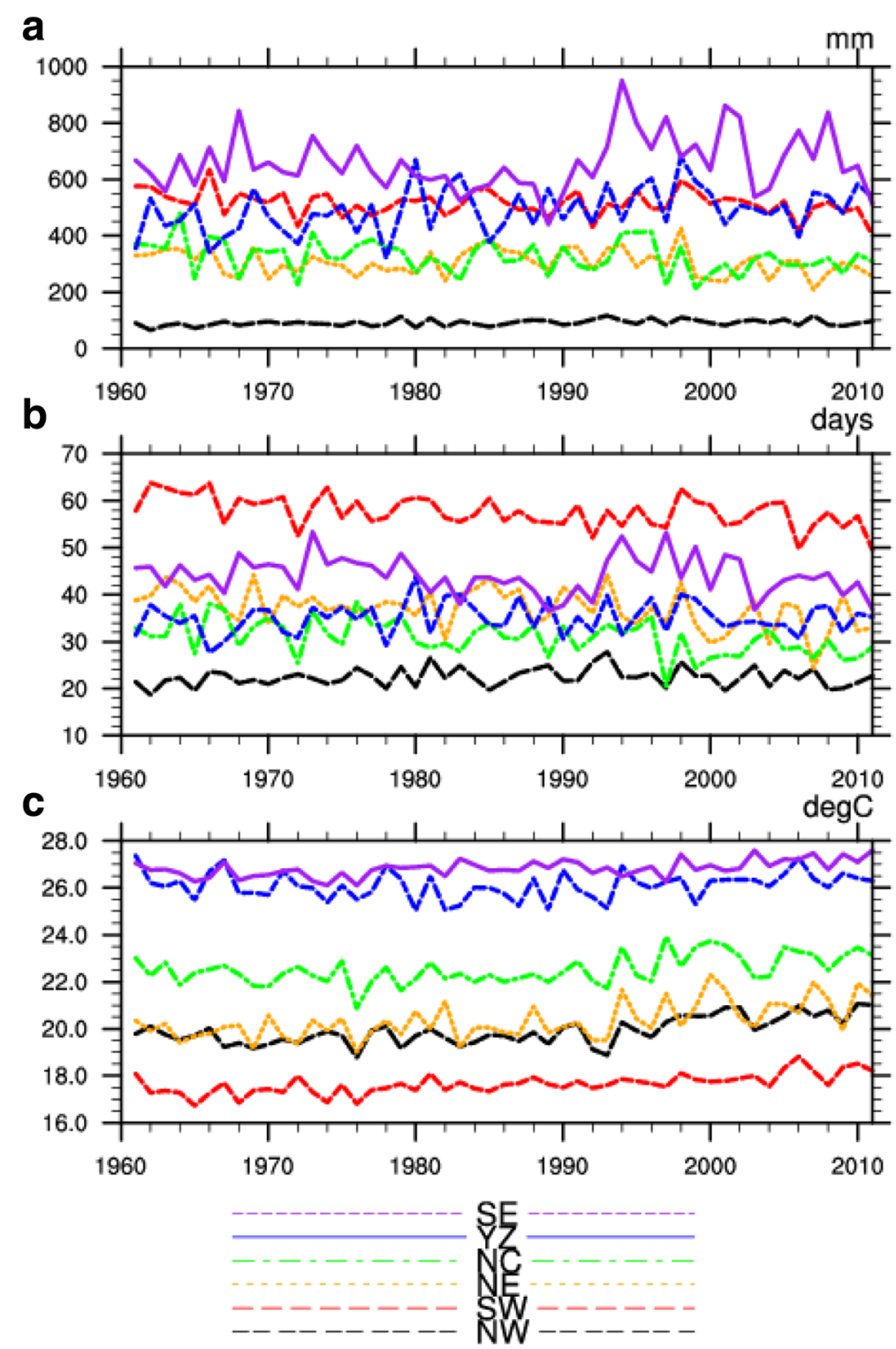

Fig. 3 Subregional climate changes from 1961 to 2011 in summer a rainfall amount, b rainfall days, and c temperature 
Table 1; red and blue values passed the 0.95 significance test, and yellow values passed the 0.9 significance test.

The distribution pattern of summer precipitation is similar to that in winter, with a maximum amount of about $700 \mathrm{~mm}$ in SE and a minimum amount of about $100 \mathrm{~mm}$ in NW; the period of relatively higher precipitation in SE is after 1990 (Fig. 3a). Variation in the number of precipitation days is also consistent with the precipitation amount, but the maximum number of precipitation days is in SW, where it reaches about 60 days each year, which is larger than in SE, indicating that there is more heavy and torrential precipitation in SE than in SW. The number of precipitation days shows a decreasing trend over SW, which is responsible for the decline in the precipitation amount in this region. The lowest number of precipitation days is in NW, with only about 20 days each year. The temperature in summer decreases northward, with the highest mean temperature about $27^{\circ}$ in SE, and it also shows an increasing trend in all six subregions.

\section{Drought and flood events evaluated by SPI-03 in different subregions}

The variation in drought and flood events in China in the past decades is examined by using the regional SPI-03, which is calculated based on 3 months of accumulated precipitation in each subregion. A flood event is defined when the maximum SPI-03 is greater than 1.0; it begins when the SPI-03 first becomes positive and ends when the SPI-03 turns negative. The opposite is defined as a drought event (McKee et al. 1993). Flood and drought intensities are defined using the maximum/minimum SPI-03 as moderate $(1.0 /-1.0)$, severe $(1.5 /-1.5)$, and extreme $(2.0 /-2.0)$. Flood and drought magnitudes can be measured as the accumulated SPI-03 during each event. The

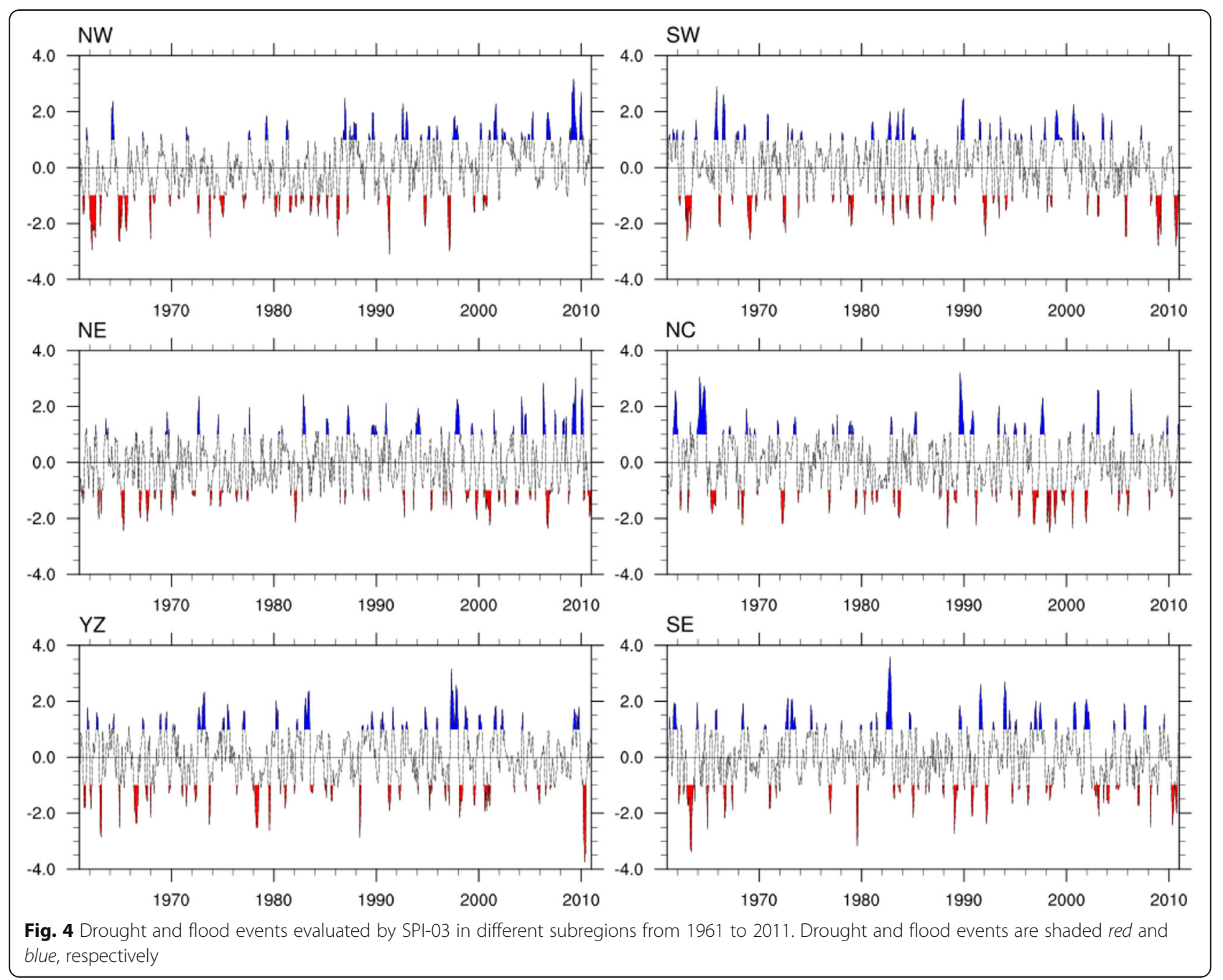


variations of regional SPI-03 are displayed in Fig. 4, where the flood and drought events are marked by shading.

It is observed that both the intensity and frequency of flood events in NW and NE have been increasing during the past decades, which is consistent with the enhancement of precipitation in these regions. Flood and drought events vary from year to year in SW, but during the last decade, SW has tended to experience less severe flood events. Extreme floods in eastern China can lead to considerable damage, as occurred with the most extreme floods with SPI-03 values above 3.0 in 1964 and 1989 in $\mathrm{NC}$, in 1998 in $\mathrm{YZ}$, and in 1983 in SE.
Since the 2000s, there have been fewer drought events affecting NW and more drought events affecting SW. The frequency and intensity of droughts have also tended to decrease over YZ and SE. As drought can influence larger areas than floods, a drought event can appear in more than one subregion, such as the drought that occurred in 2011, which first emerged in 2010 in YZ, where it reached a peak of less than - 3.0, and then spread to SE and SW in 2011.

\section{Climate mean of the water vapor budget via each regional boundary}

Climatically, water vapor is mainly transported zonally during winter. The western boundary is the main
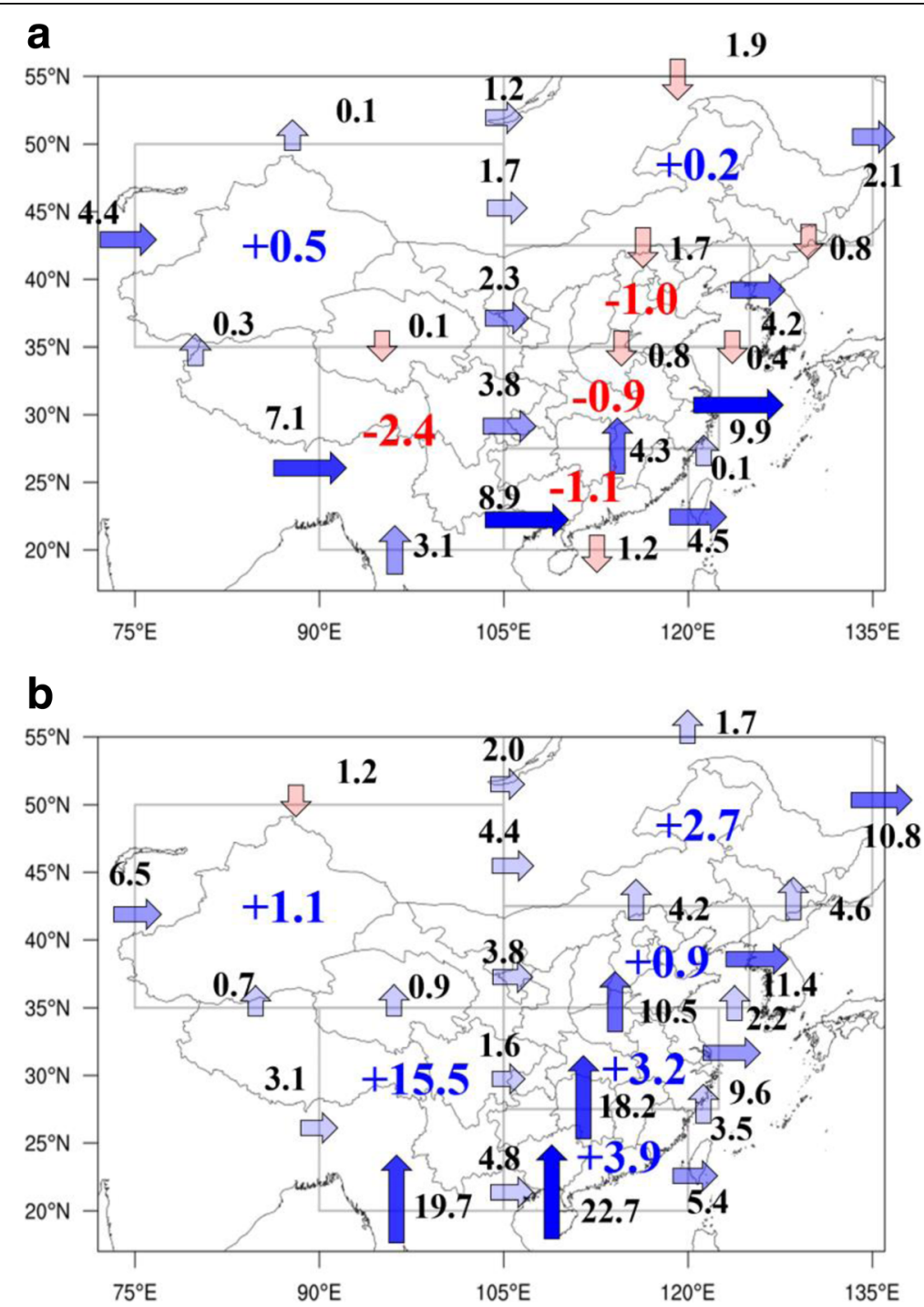

Fig. 5 Climate mean (1961-2011) of the water vapor budget via each regional boundary in winter (a) and summer (b). The numbers in black represent the amount of water vapor (unit $1 \mathrm{e} 8 \mathrm{~kg} / \mathrm{s}$ ) transport via each boundary, and numbers in red (b/ue) represent divergence (convergence) of water vapor in this region. The arrows represent the transport direction of water vapor, the red represents from north to south, and blue represents from west to east or from south to north 
input boundary and is much stronger than the southern boundary for western China and the northern boundary for eastern China, and the main output boundary is the eastern boundary. There are two water vapor convergence subregions: the moisture budget is $+0.5 \times 10^{8} \mathrm{~kg} / \mathrm{s} \quad\left(+4.4 \times 10^{8} \mathrm{~kg} / \mathrm{s}\right.$ from the west, $+0.2 \times 10^{8} \mathrm{~kg} / \mathrm{s}$ from the south, $-4.0 \times 10^{8} \mathrm{~kg} / \mathrm{s}$ from the east, $-0.1 \times 10^{8} \mathrm{~kg} / \mathrm{s}$ from the north) in NW and $+0.2 \times 10^{8} \mathrm{~kg} / \mathrm{s}$ in NE. And other subregions are water vapor divergence regions, with $-2.4 \times 10^{8}$, $1.0 \times 10^{8},-0.9 \times 10^{8}$, and $-1.1 \times 10^{8} \mathrm{~kg} / \mathrm{s}$ in SW, NC, $\mathrm{YZ}$, and SE, respectively. During summer, the main input boundary is the southern boundary, which shows a strong gradient from south to north, and water vapor is transported from the ocean to the mainland by the monsoon flow. Another input boundary is the western boundary, but it is much weaker than the southern boundary. The main output boundaries are the northern and eastern boundaries. All six subregions are water vapor convergence regions, with $+1.1 \times 10^{8},+15.5 \times 10^{8},+2.7 \times 10^{8},+$
$0.9 \times 10^{8},+3.2 \times 10^{8}$, and $+3.9 \times 10^{8} \mathrm{~kg} / \mathrm{s}$ in $\mathrm{NW}, \mathrm{SW}$, NE, NC, YZ, and SE, respectively, (Fig. 5).

The long-term changes in the water vapor budget and water vapor transport via each regional boundary are shown in Figs. 6 and 7 for winter and summer, respectively. If we compare the variations in the moisture budget and precipitation amount, it is clear that the moisture budget plays a very important role in the variation of precipitation in different subregions. During winter, the correlation coefficient between precipitation and moisture budgets can reach above 0.7 in NW and $\mathrm{SE}$, and during summer, the coefficients are 0.632 for $\mathrm{NE}, 0.512$ for $\mathrm{NC}, 0.402$ for $\mathrm{YZ}$, and 0.726 for SE, all of which pass the 0.95 significance test.

During winter, as moisture transported from the western boundary is the main input source and the eastern boundary is the main output source, the variations in moisture transport via these two boundaries are relatively important to precipitation variability (Fig. 6). In $\mathrm{NW}$, the moisture input via the western boundary increases notably, while the moisture output from the

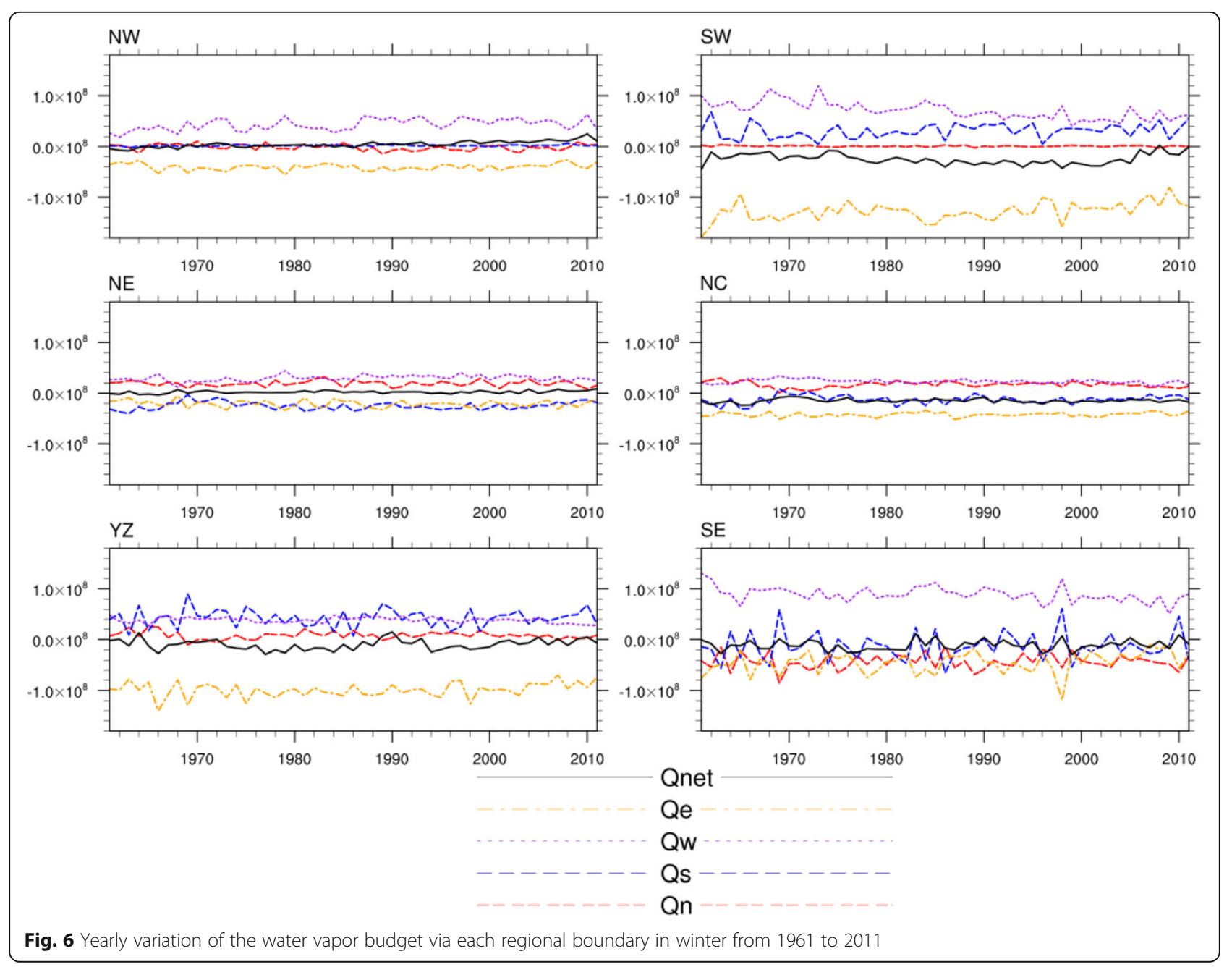




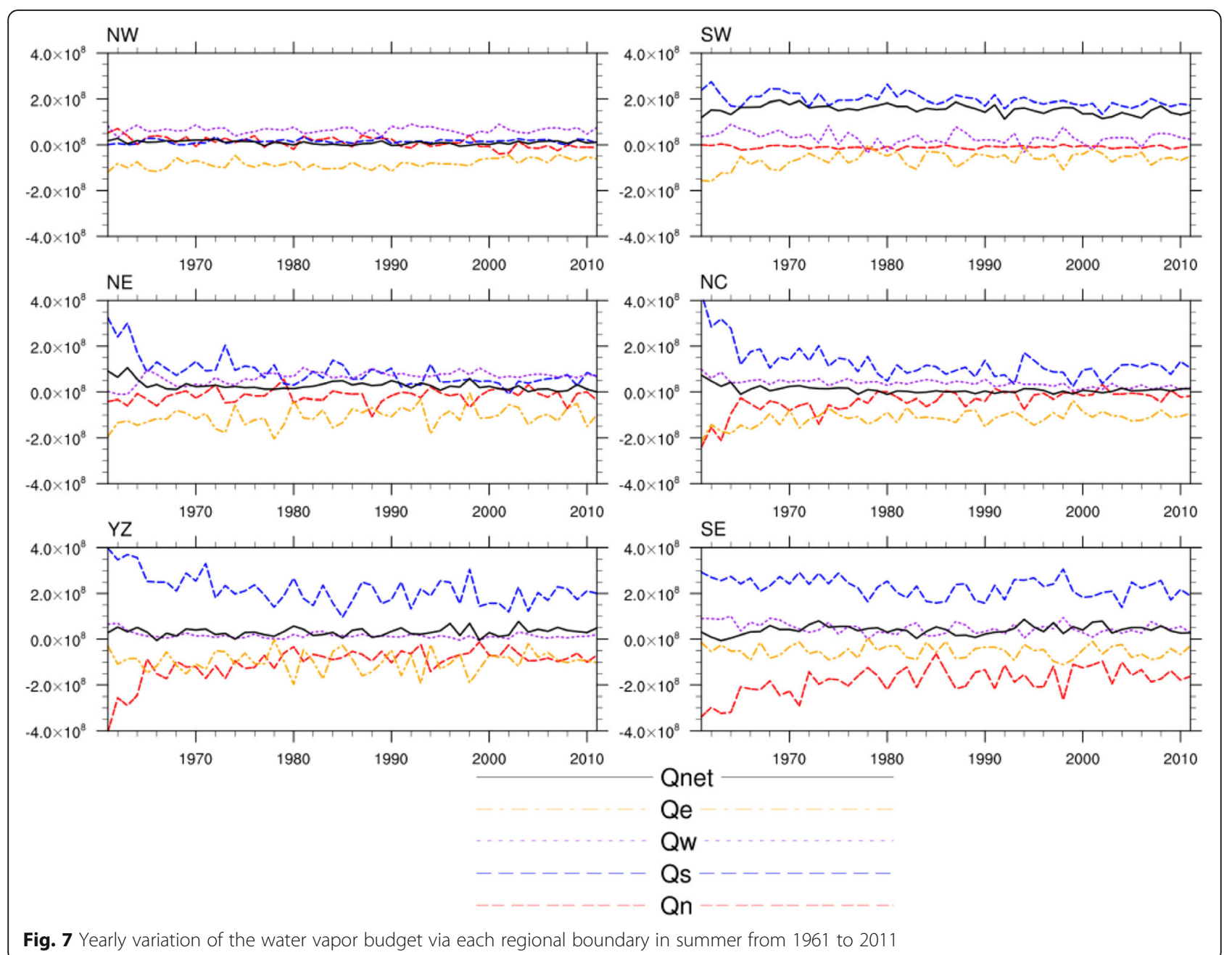

eastern boundary remains unchanged, which results in the enhancement of the moisture budget in this region. In eastern China (NC, YZ, and SE), both the input moisture from the western boundary and the output moisture from the eastern boundary are slightly weakened; thus, the total amount of regional moisture in these subregions does not change much.

During summer, zonal transport is also dominant in NW, and the input from the western boundary does not change much, while both the moisture input from the north and the output from the east decrease. The water vapor budget in SW is affected mainly by the moisture transported from the southern boundary; they vary together and show a decreasing trend. Meridional transport is much stronger than zonal transport in eastern China (NC, YZ, and SE). The strength of the meridional transport has weakened during the past decades, which is associated with the weakening of the East Asian summer monsoon. The decline in input moisture from the south is slightly weaker than the decline in output moisture via the northern boundary; therefore, the net moisture budget is slightly increased in eastern China. Compared to the meridional transport, the input moisture via the western boundary and output moisture via the eastern boundary do not change much (Fig. 7). During winter, the correlation coefficient between precipitation and the moisture budget can reach above 0.7 in NW and SE (Fig. 8), and during summer, the coefficients are 0.632 for NE, 0.512 for $\mathrm{NC}, 0.402$ for $\mathrm{YZ}$, and 0.726 for SE, respectively, (Fig. 9), all of which pass the 0.95 significance test.

\section{Drought and flood risk under ENSO conditions}

Rainfall in China is strongly influenced by the East Asian monsoon system, which exhibits seasonal, annual, and decadal variations as the global circulation patterns vary on various timescales. Meteorologists are trying to understand the ENSO signals that interact with monsoon rainfall, and how they are superimposed on monsoon rainfall or otherwise modify monsoon rainfall (e.g., Huang and Wu 1989; Wang and Fan 1999; Wang et al. 2000; Chen et al. 2000; Zhou and Chan 2007; Wang et 


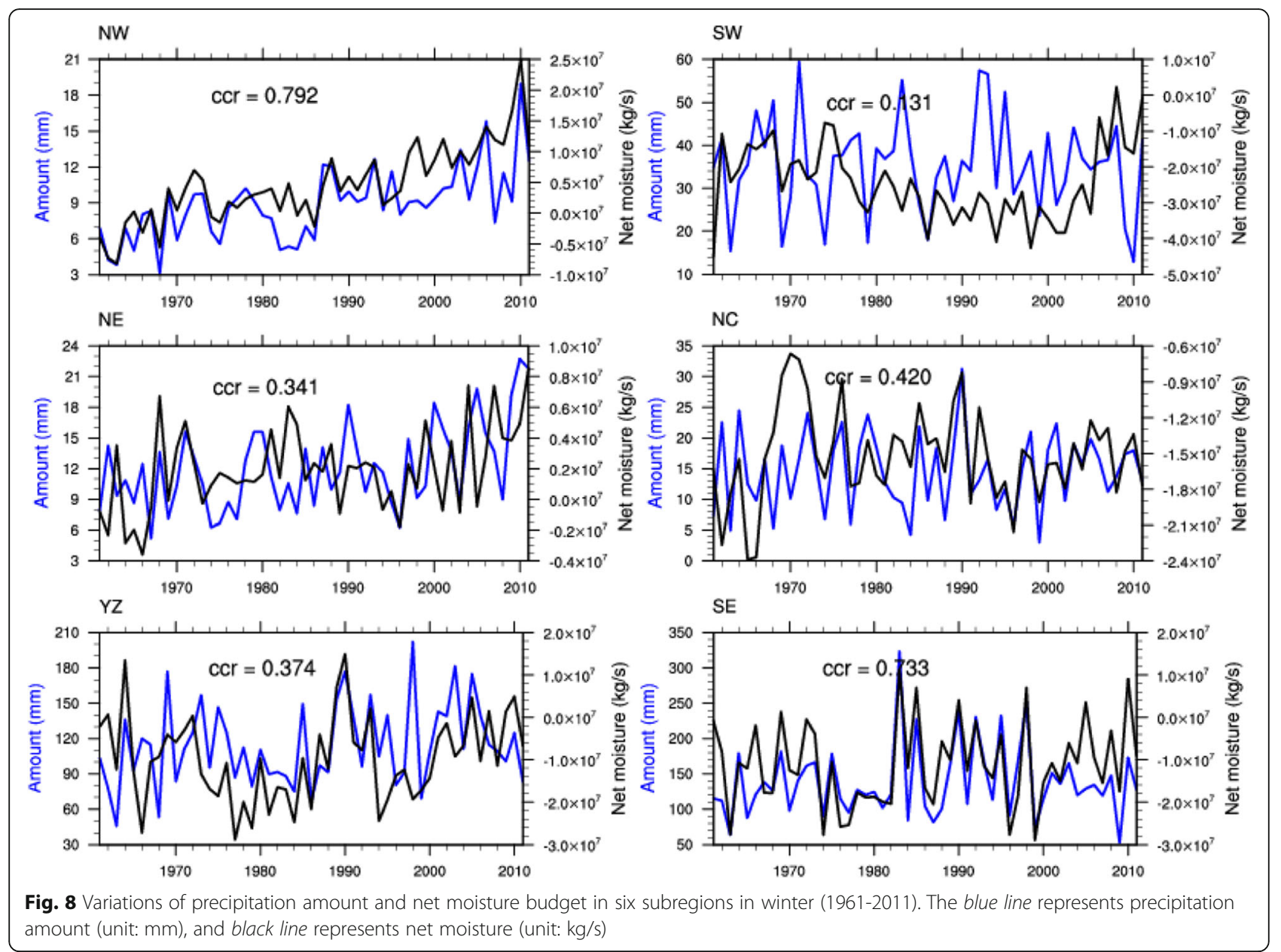

al. 2014; Leung and Zhou 2016). Zhang and Sumi (2002) suggested that ENSO has a significant impact on rainfall in China, as ENSO affects the transport of moisture by the East Asian monsoon system. It is understood in general that rainfall anomalies in South China are the manifestations of global atmosphere-ocean and atmosphereland interactions, which are most directly related to SST anomalies in the Pacific and Indian Oceans, snow cover on the Tibetan Plateau, and soil moisture on the Eurasian continent. Huang and Wu (1989) found that the developing (decaying) stage of a warm ENSO event is associated with drought (flood) in southern and northern China and flood (drought) in central China. Following the study of Li et al. (2015), we also investigated drought and flood risk under ENSO conditions. The ratio of the probability of flood/drought under ENSO to the probability of flood/drought under all conditions is calculated in order to study the drought and flood risk in different subregions. Flood (drought) is defined when SPI-03 is greater (smaller) than 1.0 (1.0) (Fig. 10). When the value of the ratio is greater (smaller) than 1.0, it represents a higher (lower) risk under ENSO than normal. The risk of drought/flood under ENSO during winter and the decaying summer is displayed in Fig. 8. During winter, the mature stage of El Niño has a great influence on drought and flood risk in China. The value of the ratio is around 0.5, which indicates much less drought risk under El Niño. Consistently, five of the six subregions tend to have much higher flood risk. During the decaying summer, El Niño has a similar influence on China except in SW and SE, where there is lower drought risk and higher flood risk. The maximum flood risk is in YZ, which indicates that this area would experience more flooding during an El Niño decaying summer; the flood risk reaches as high as 1.7. The condition reverses during a La Niña winter and the following summer. During a La Niña winter, the whole of China is more likely to suffer more droughts and fewer floods, and the drought risk reaches as low as 0.5 in $\mathrm{YZ}$, but the risk is lower than in an El Niño year compared to the flood risk of 1.9. During a La Niña decaying summer, similarly, there is more drought risk and less flood risk, especially in northern China (Fig. 10). 

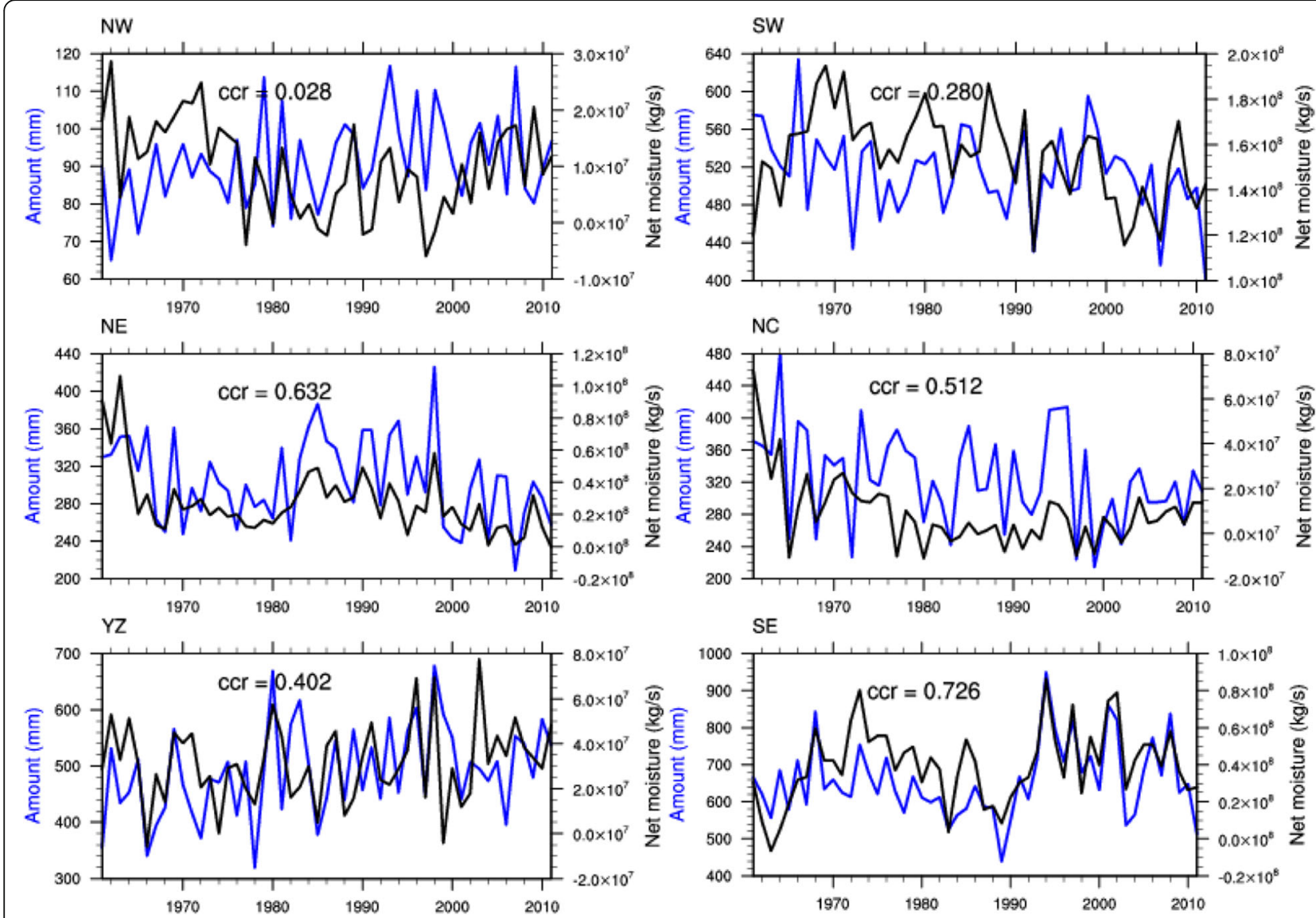

Fig. 9 Same as Fig. 8 but for summer

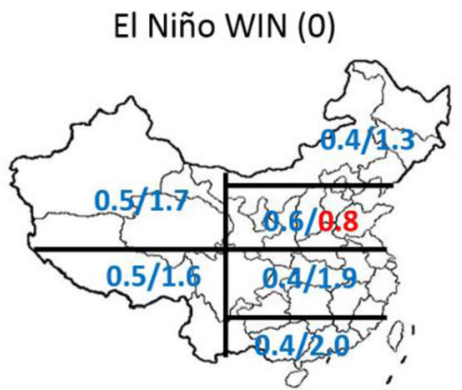

El Niño SUM (+1)

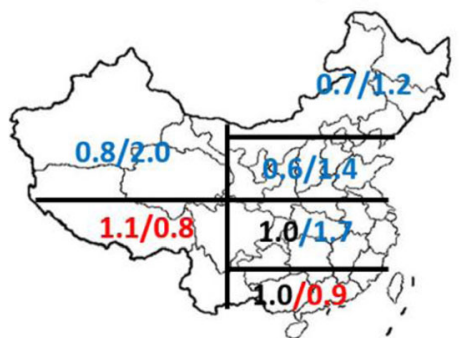

La Niña WIN (0)

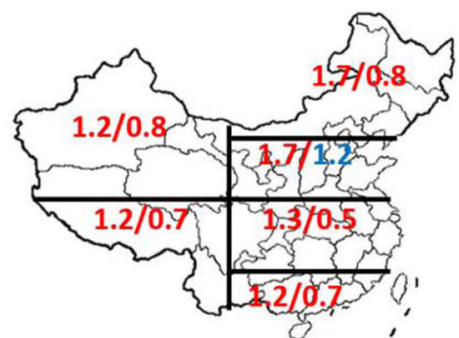

La Niña SUM (+1)

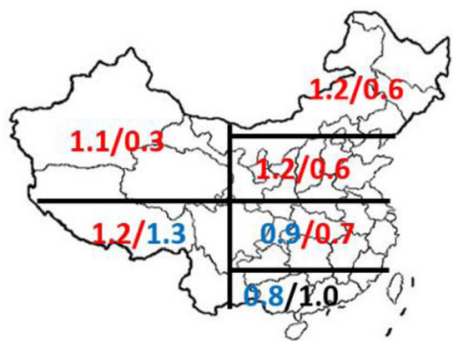

Fig. 10 Drought/flood risk in different subregions during an El Niño year (left) and a La Niña year (right). The blue color represents higher flood risk, and red color represents higher drought risk 
It is important to point out that we used data from stations in China to calculate the precipitation, while we used grid data to calculate the water vapor budget. The grid data may cover a larger region compared to China, for example, in SW, the water vapor budget is larger than in only the SW of China, thus possibly causing inaccuracy.

\section{Conclusions}

Drought and flood events are investigated in different subregions by using the SPI-03 index, and it is found that the frequency and intensity of floods in NW have increased while droughts have decreased in recent decades, but the situation is reversed in SW. In YZ and SE, flood conditions tend to be slightly intensified and drought conditions slightly weakened.

The variation in drought and flood conditions is associated with the changes in water vapor transport in these subregions. Water vapor in NW is mainly transported zonally during both winter and summer, with a significant enhancement of input moisture and decline of output moisture, which contributes to the increase of flood events and the decrease of drought events in this region. Floods and droughts in YZ and SE are affected mainly by meridional transport from south to north during summer, which provides a slightly increased moisture budget in these regions.

ENSO is a crucial driver of precipitation in China, as it can modulate the atmospheric circulation. The impact of El Niño on flood and drought events indicates that El Niño tends to increase the flood risk over most parts of China, except the SW and SE during the decaying summer. The wetter than normal condition is probably partly due to the abundant moisture transported by the anomalous southerlies into southeastern China, leading to moisture convergence in this region during winter. In the decaying summer, moisture convergence occurs over $\mathrm{YZ}$ and $\mathrm{NC}$ and moisture divergence occurs over SE, which results in higher flood risk in $\mathrm{YZ}$ and $\mathrm{NC}$ and a higher drought risk in SE.

\begin{abstract}
Abbreviations
CMA: China Meteorological Administration; ENSO: El Niño-Southern Oscillation; NC: North China; NCAR: National Center for Atmospheric Research; NCEP: National Centers for Atmospheric Prediction; NE: Northeast China; NW: Northwest China; QE: Moisture transport across the eastern boundary; QN: Moisture transport across the northern boundary; Qnet: Net regional atmospheric moisture budget; QS: Moisture transport across the southern boundary; QW: Moisture transport across the western boundary; SAT: Surface air temperature; SE: Southeast China; SPI: Standard Precipitation Index; SW: Southwest China; YZ: Yangtze River valley
\end{abstract}

\section{Acknowledgements}

The first author is a recipient of a research studentship provided by the City University of Hong Kong, and this work is supported by the National Natural Science Foundation of China (Grant No. 41375096) and the Research Grants Council of the Hong Kong Special Administrative Region, China (Grant No. 11305715). We also thank the suggestions and constructive comments of the reviewers and editor.

\section{Funding}

This work was supported by the National Natural Science Foundation of China (Grant No. 41375096) and the Research Grants Council of the Hong Kong Special Administrative Region, China (Grant No. 11305715).

\section{Authors' contributions}

SQ wrote the paper and plotted the figures. WZ designed the experiments and discussed the results. MYTL and XL provided the observation datasets and calculated SPI index. All authors read and approved the final manuscript.

\section{Competing interests}

The authors declare that they have no competing interests.

\section{Publisher's Note}

Springer Nature remains neutral with regard to jurisdictional claims in published maps and institutional affiliations.

\section{Author details}

${ }^{1}$ Guy Carpenter Asia-Pacific Climate Impact Center, School of Energy and Environment, City University of Hong Kong, Tat Chee Ave., Kowloon, Hong Kong SAR, China. ${ }^{2}$ Center for Monsoon and Environment Research and Department of Atmospheric Sciences, Guangdong Province Key Laboratory for Climate Change and Natural Disaster Studies, Sun Yat-sen University, Guangzhou 510275, China.

Received: 8 March 2017 Accepted: 8 November 2017

Published online: 07 December 2017

\section{References}

Bowman AW, Azzalini A (1997) Applied smoothing techniques for data analysis: the kernel approach with S-plus illustrations. Oxford Statistical Science Series, Vol. 18, Oxford University Press, 193 pp.

Chen W, Graf H-F, Huang RH (2000) The interannual variability of East Asian winter monsoon and its relation to the summer monsoon. Adv Atmos Sci $17: 48-60$

Ding YH (2007) The variability of the Asian summer monsoon. J Meteor Soc Japan 85B:21-54

Ding YH, Sun Y (2001) A study on anomalous activities of East Asian summer monsoon during 1999. J Meteor Soc Japan 79:1119-1137

Huang R, Wu Y (1989) The influence of ENSO on the summer climate change in China and its mechanism. Adv Atmos Sci 6:21-32

Jhun JG, Lee EJ (2004) A new East Asian winter monsoon index and associated characteristics of the winter monsoon. J Clim 17:711-726

Kalnay E et al (1996) The NCEP/NCAR 40-year re-analysis project. Bull Amer Meteor Soc 77:437-470

Lei YH, Duan AM (2011) Prolonged dry episodes and drought over China. Int J Climatol 31:1831-1840

Leung YT, Zhou W (2016) Direct and indirect ENSO modulation of winter temperature over the Asian-Pacific-American region, Sci Rep doi:10. 1038/srep36356

Li XZ, Zhou W, Chen Y (2015) Assessment of regional drought trend and risk over China: a drought climate division perspective. J Clim 28:7025-7037

Li XZ, Zhou W, Wen ZP (2011) Long-term change in summer water vapor transport over south China in recent decades. J Meteor Soc Japan 89A:271-282

Lin AL, Li CH, Gu DJ, Zheng B (2012) Variation and causes of persistent drought events in Guangdong Province. J Trop Meteor 18:54-64 (in Chinese)

Ma S, Zhou T, Dai A, Han Z (2015) Observed changes in the distributions of daily precipitation frequency and amount over China from 1960 to 2013. J Clim 28:6960-6978

McKee TB, Doesken NJ, Kleist J (1993) The relationship of drought frequency and duration to time scales. Proc Eighth Conf on Applied Climatology, Anaheim, CA, Amer Meteor Soc:179-184

Schmitz JT, Mullen SL (1996) Water vapor transport associated with the summertime North American monsoon as depicted by ECMWF analyses. J Clim 9:1621-1634

Simmonds I, Bi DH, Hope P (1999) Atmospheric water vapor flux and its association with rainfall over China in summer. J Clim 12:1353-1367

Trenberth KE (1991) Climate diagnostics from global analyses: conservation of mass in ECMWF analyses. J Clim 4:707-722 
Trenberth KE (1999) Atmospheric moisture recycling: roles of advection and local evaporation. J Clim 12:1368-1381

Wang B, Fan Z (1999) Choice of South Asian summer monsoon indices. Bull Amer Meteor Soc 80:629-638

Wang B, Wu R, Fu X (2000) Pacific-East Asian teleconnection: how does ENSO affect East Asian climate? J Clim 13:1517-1536

Wang HJ, Chen HP (2012) Climate control for southeastern China moisture and precipitation: Indian or East Asian monsoon? I Geophys Res 117:D12109

Wang L, Chen W, Huang RH (2008) Interdecadal modulation of PDO on the impact of ENSO on the East Asian winter monsoon. Geophys Res Lett 35:L20702. doi:10.1029/2008GL035287

Wang WW, Zhou W, Chen DL (2014) Summer high temperature extremes in southeast China: bonding with the El Niño-Southern Oscillation and East Asian summer monsoon coupled system. J Clim 27:4122-4138

Wei JF, Dirmeyer PA, Bosilovich MG, Wu R (2012) Water vapor sources for Yangtze river valley rainfall: climatology, variability, and implications for rainfall forecasting. J Geophys Res 117:D05126

Wen C, Graf HF, Huang RH (2000) The interannual variability of East Asian winter monsoon and its relation to the summer monsoon. Adv Atmos Sci 17:48-60

Zhai P, Zhang X, Wan H (2005) Trends in total precipitation and frequency of daily precipitation extremes over China. J Clim 18:1096-1108

Zhang Q, Xu CY, Jiang T, Wu YJ (2007) Possible influence of ENSO on annual maximum streamflow of the Yangtze river, China. J Hydrol 333:265-274

Zhang RH, Sumi A (2002) Moisture circulation over East Asia during El Niño episode in northern winter, spring and autumn. J Meteor Soc Japan 80:213-222

Zhang Y, Sperber KR, Boyle JS (1997) Climatology and interannual variation of the East Asian winter monsoon: results from the 1979-95 NCEP/NCAR reanalysis. Mon Wea Rev 125:2605-2619

Zhao P, Zhou XJ (2006) Decadal variability of rainfall persistence time and rain belt shift over eastern China in recent 40 years. J Appl Meteor Sci 17:548-556

Zhou W, Chan JCL (2007) ENSO and the South China Sea summer monsoon onset. Int J Climatol 27:157-167

\section{Submit your manuscript to a SpringerOpen ${ }^{\circ}$ journal and benefit from:}

- Convenient online submission

- Rigorous peer review

- Open access: articles freely available online

- High visibility within the field

- Retaining the copyright to your article

Submit your next manuscript at $\gg$ springeropen.com 